References

1 Young ID, Simpson K. Unknown syndrome: abnormal facies, congenital heart defects, hypothyroidism, and severe retardation. $J$ Med Genet 1987;24:715-6.

2 Fryns JP, Moerman P. Unknown syndrome: abnormal facies, hypothyroidism, and severe retardation: a second patient. $J \mathrm{Med}$ Genet 1988;25:498-9.

Correspondence to Dr D P Cavalcanti, Departamento de Genética Médica, FCM, UNICAMP, CP 6111, 13081 Campinas, SP, Brazil.

\section{Unknown syndrome: microcephaly, hypoplastic nose, exophthalmos, gum hyperplasia, cleft palate, low set ears, and osteosclerosis}

SUMMARY We report a neonate, born at term, with microcephaly, a hypoplastic nose, exophthalmos, gum hyperplasia, cleft palate, and low set ears, who died at 86 minutes of age. Radiographs showed diffuse sclerosis of the bones.

Received for publication 10 April 1989. Accepted for publication 23 May 1989.

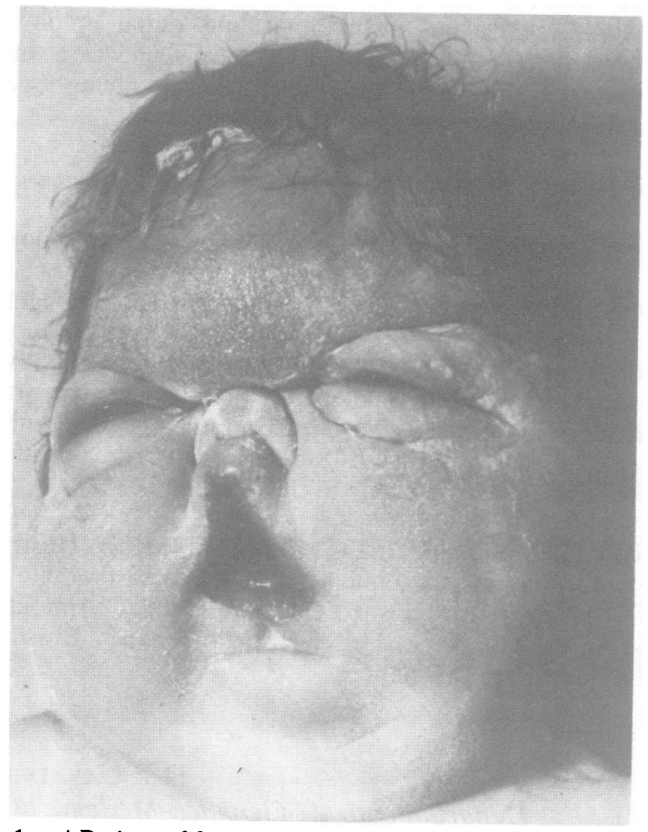

FIG 1 AP view of face.
FIG 2 Lateral view of face.

\section{History}

Prenatal. No infections or drugs in pregnancy.

Birth. Cephalic delivery at term. Female infant. Weight $2730 \mathrm{~g}$ (10th centile), length $44.5 \mathrm{~cm}$ ( $<3$ rd centile), and occipitofrontal circumference $30 \mathrm{~cm}$ ( $<3 \mathrm{rd}$ centile). Apgar scores 8 at one and five minutes. Noted to be hypotonic.

Family. Healthy, unrelated, Caucasian parents. One healthy daughter. One stillbirth at term after placental abruption: normal baby. One first trimester miscarriage. No family history of congenital abnormalities.

\section{Clinical examination (figs 1, 2, and 3)}

Microcephaly. Sagittal suture $5 \mathrm{~cm}$ wide with large anterior and posterior fontanelles. Ridged coronal sutures. Marked exophthalmos. Maxillary hypoplasia with a sunken nasal bridge and micrognathia. Bowed upper lip. Cleft in soft palate and uvula. Hyperplastic premaxillary and mandibular gums. Low set ears.

\section{Subsequent course}

Placed in a cot in the special care baby unit. Respiratory distress developed within $\mathbf{3 0}$ minutes of birth, presumably secondary to pulmonary hypoplasia. Because of the multiple severe abnormalities a policy of conservative treatment was adopted. Gasping at 80 minutes at age, she died at 86 minutes of age. 


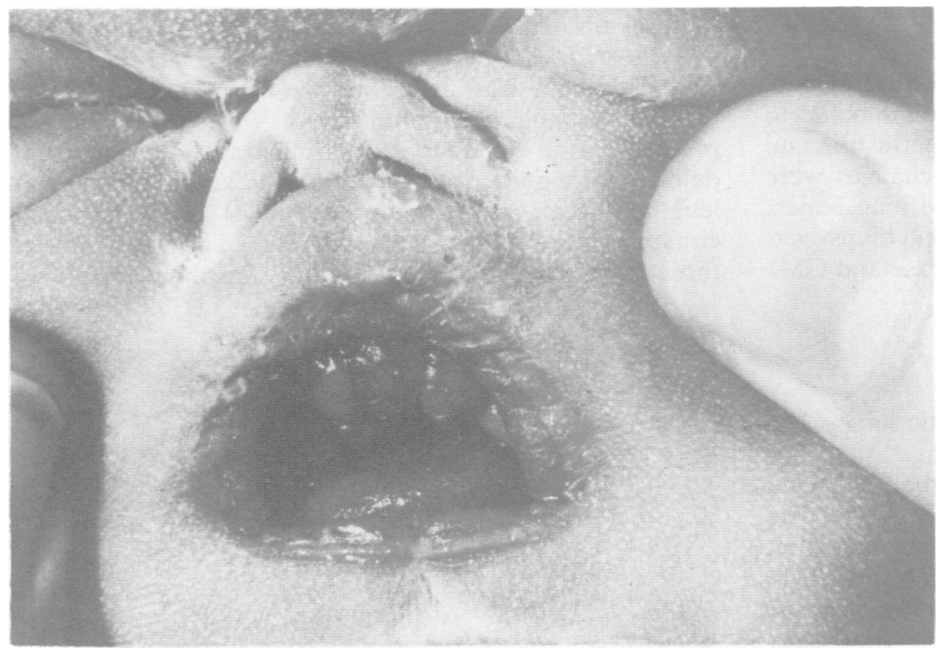

FIG 3 Close up of mouth.

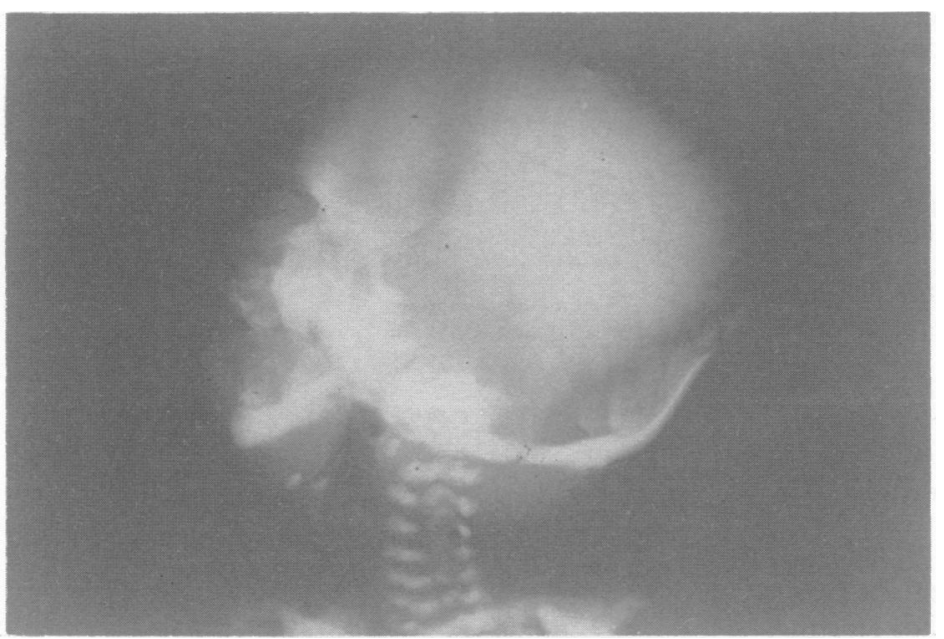

\section{FIG 4 Lateral skull radiograph.}

FIG 5 Radiograph of chest and upper abdomen. 


\section{Investigations}

Chromosomes (G banded) showed a normal female karyotype. Radiological examination showed the bones to be generally osteosclerotic with extensive periostitis and metaphyseal flaring (figs 4 and 5). These changes were particularly marked in the skull, pelvis, and long bones. Enzymology on cultured fibroblasts from a skin biopsy was normal and in particular excluded I cell disease and GM1 gangliosidosis.

\section{Necropsy findings}

Macroscopic examination showed hypoplastic lungs. The lungs weighed half their joint expected weight of $50 \mathrm{~g}$. The liver and spleen were one and a half times their expected weight, weighing $15.4 \mathrm{~g}$ and $11 \mathrm{~g}$ respectively. The adrenal glands were hyperplastic; the right and left adrenals weighed $5.8 \mathrm{~g}$ and $6.3 \mathrm{~g}$ respectively, which is almost twice their expected weight. The brain was of normal size weighing $310 \mathrm{~g}$. The contours of the brain were distorted by the shape of the skull but fissures and sulci appeared normal. There were no other abnormal findings on macroscopic examination.

\section{Discussion}

In spite of a detailed search of published reports we were unable to find any cases such as the one we have described.

We would like to thank Dr V Mitchell and Dr S Gilani for their help regarding the radiological aspects of this case.

\section{J Raine, R M Winter, A Davey, ANd S M Tucker Kennedy Galton Centre, Northwick Park Hospital,} Harrow, Middlesex HA1 $3 U$ J.

Correspondence to $\operatorname{Dr} \mathbf{R}$ M Winter, Kennedy Galton Centre, Clinical Research Centre, Northwick Park Hospital, Watford Road, Harrow, Middlesex HA1 3UJ.

\section{Unknown syndrome: pachygyria, joint contractures, and facial abnormalities}

SUMmaRY A male infant, the offspring of a fatherdaughter mating, is described. He had a lethal condition consisting of brachycephaly, large fontanelles, a flat face, a small nose with thin nares, hypertelorism, small ears with cystic pinnae, camptodactyly, talipes equinovarus, and hypoplastic lungs and kidneys. The brain was very short in the anterior-posterior diameter with simplified broad convolutions (a form of pachygyria).

\section{Medical history}

This male baby was apparently the offspring of a fatherdaughter mating. The parents were West Indian and the mother was a 15 year old primipara. Pregnancy and delivery were normal. Birth weight was $3200 \mathrm{~g}$, crown-heel length $49 \mathrm{~cm}$, crown-rump length $34 \mathrm{~cm}$, and head circumference $31.5 \mathrm{~cm}(<3 \mathrm{rd}$ centile). The baby died at three hours of age from respiratory insufficiency.

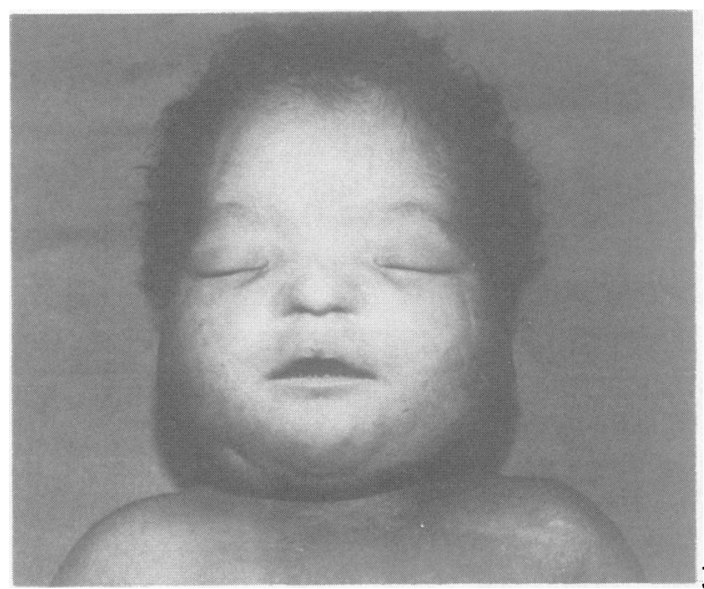

FIG 1 The face at necropsy.

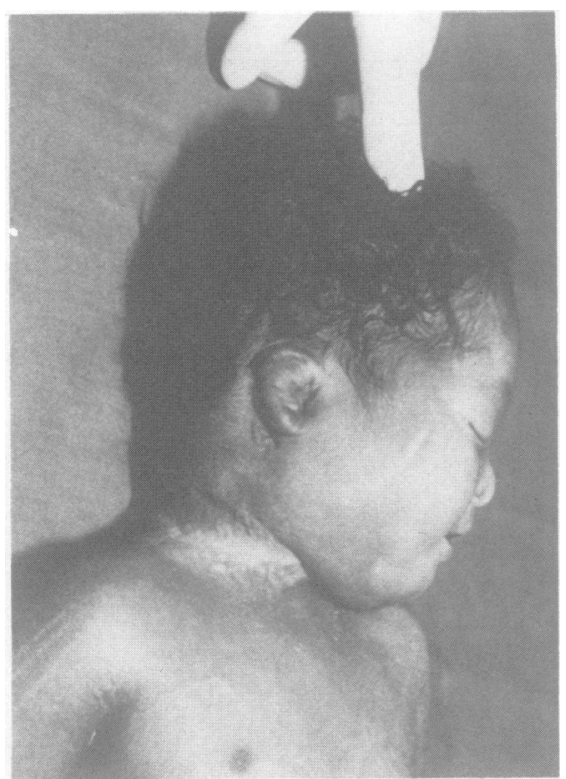

FIG 2 Lateral view of head at necropsy; note cystic ear pinna. 